\title{
Geographie und Dritte Welt - Verantwortung und Zukunft
}

\section{Die Zukunft unseres Lebensraumes - eine Herausforderung an die Geographie}

Die Zukunft unseres Lebensraumes ist ein Leitthema, das eine echte Herauforderung für die Geographie von heute bedeutet, wenn sie sich herausfordern läßt. Mit diesem kleinen Nachsatz nehmen wir diejenige Geographie ins Visier, die sich noch in der jüngsten Vergangenheit in innere Zweifel verstrickte und ihre besten Kräfte vergeudete, um die wissenschaftstheoretische Unvereinbarkeit von physischer Geographie und Kulturgeographie zu beweisen. Sie bemerkte nicht einmal, daß die Beziehung Mensch-Natur oder Mensch-Umwelt als ureigenstes Anliegen der Geographie zu einem der grundlegendsten Probleme unserer Zeit und unserer Zukunft wurde, daß der Ruf unserer Gesellschaft nach neuen verbindenden Denkmustern und Lösungen sich immer drängender manifestierte. daß sich zahlreiche andere Disziplinen unbekümmert um theoretische Überlegungen überaschend diesen Fragen öffneten, daß schließlich zahlreiche internationale Organisationen ihr ganzes Prestige einsetzten, um die Wissenschaften von neuen Richtungen mit intensivem Zusammenwirken von naturund sozialwissenschaftlichen Ansätzen zu überzeugen.

Ganz unmißverständlich und fast provokativ möchte ich feststellen, daß die Geographie mit ihrem natürlichen und anthropogenen Raumbezug jetzt und in Zukunft eine bedeutende Rolle spielen kann, sie hat die Voraussetzungen, sie muß nur wollen: Bedeutende Impulse und weiterführende Ideen sind immer wieder durch die Herausforderung konkreter und drängender Fragen und nicht durch abstrakte Überlegungen im luftleeren Raum entstanden.

Die Zukunft unseres Lebensraumes, sei es im lokalen oder regionalen, im nationalen oder selbst im globalen Maßstab, ist eine solche Herausforderung. Konkreter gesagt und auf unser Thema ausgerichtet heißt das: Die reichen Staaten des Nordens lösen mit ihrer wirtschaftlich-technischen Entwicklung Prozesse aus, die, lange nicht verstanden, Ressourcen und Umwelt von der lokalen bis zur globalen Dimension gefährden. Aber auch die armen Staaten des Südens lösen mit der Übernutzung der empfindlichen Naturgrundlagen durch die rasch wachsende
Bevölkerung Prozesse aus, die, lange nicht verstanden, Ressourcen und Umwelt gefährden. Die Fragen nach der Zukunft unseres Lebensraumes und nach dem Verhältnis zwischen Mensch und Natur von der lokalen bis zur globalen Sicht zeichnen sich als die zentralen Probleme ab für eine Welt, in der wir leben und in der wir auch in Zukunft zu leben haben werden.

Heute blickt die schweizerische Wissenschaft und Wirtschaft gebannt auf das Europa der 90er Jahre. Ein gewaltiger Umbruch in Ost und West spielt sich vor unseren Augen ab. Selbstverständlich werden die zunehmende Integration des westlichen Europas und die angepaßte Partizipation der Schweiz für uns und für die Gestaltung unseres unmittelbaren Lebensraumes von größter Bedeutung sein. Aber: Wird die Kluft zwischen einem wirtschaftlich und einem wissenschaftlich stärkeren Europa und einer wirtschaftlich und wissenschaftlich ständig weiter zurückbleibenden Dritten Welt nicht noch größer, noch beängstigender, noch provozierender? Wie werden unsere nächsten Generationen im kommenden Jahrhundert denken und handeln, wenn die Differenz zwischen Reichen und Armen noch größer geworden ist, wenn ein Teil der Dritten Welt eine wachsende Bevölkerung noch weniger zu ernähren vermag, wenn die Verteilung der knapper werdenden Ressourcen zum Problem wird und wenn das Ökosystem Erde den wachsenden Energieverbrauch nicht mehr verkraften kann? Werden alle diese Fragen nicht ein Europa überschatten, das sich heute - herausgefordert durch die Konkurrenz der hochentwickelten Industriestaaten des Nordens - zum Aufstieg in eine weltweite wirtschaftlich-wissenschaftlich-technische Spitzenposition rüstet?

Kehren wir zurück zum Problem der Dritten Welt: Vor 20 Jahren hat Hans Bösch in seiner vielbeachteten Weltwirtschaftsgeographie eine Karte der Landnutzung publiziert (Fig. 1). Eindrücklich ist die Ausdehnung des flächenhaft intensiven agrarischen Anbaus dargestellt, die die Begünstigung der mittleren Breiten der Nordhalbkugel mit aller Deutlich-

Bruno Messerli, Prof., Dr., Geographisches Institut der Universität Bern, Hallerstrasse 12, 3012 Bern 


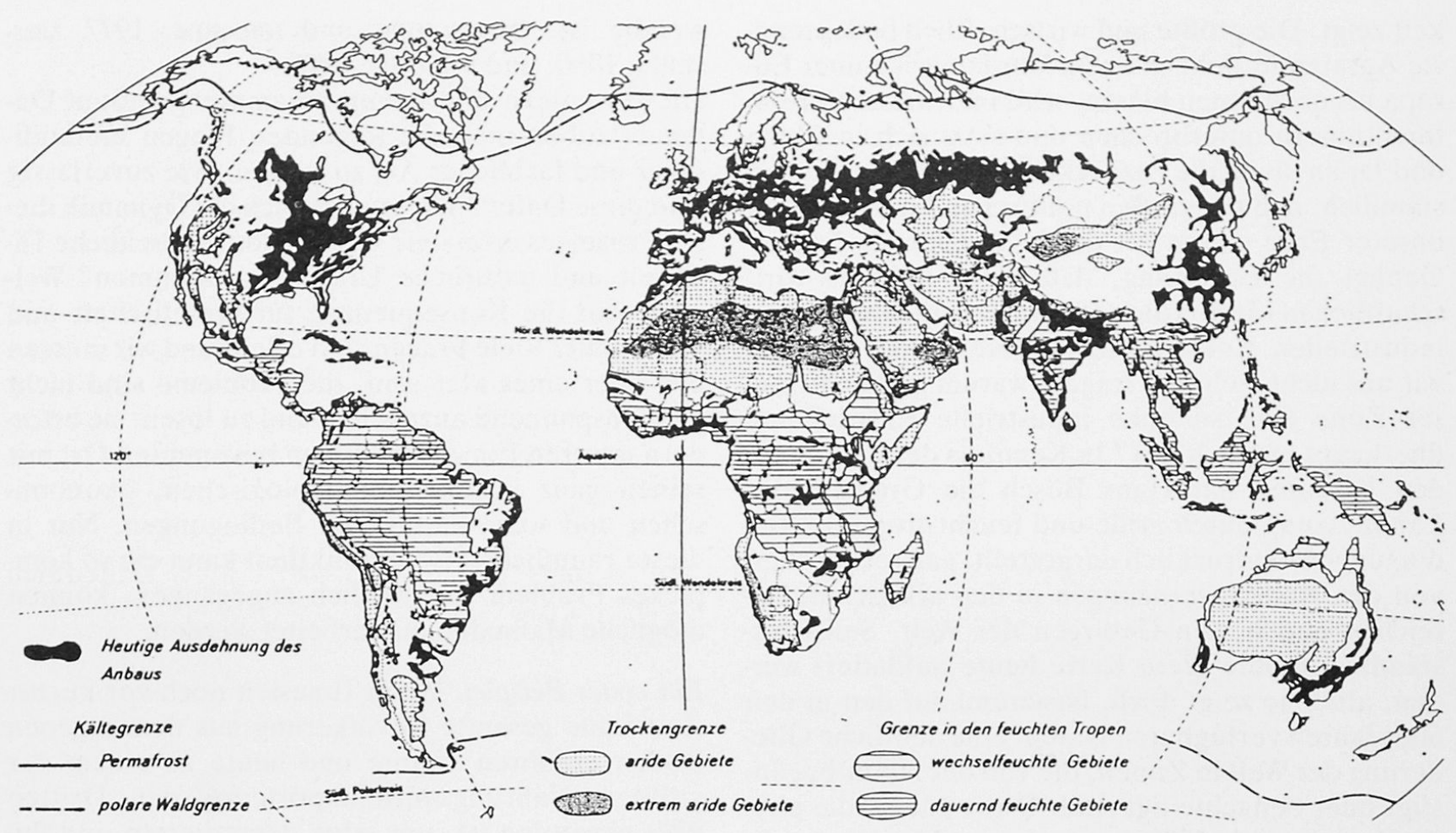

Abb. 1 Grenzen der Landwirtschaft (aus Boesch, 1969: 97)

Das Klima: Limitierender Faktor für die Landnutzung

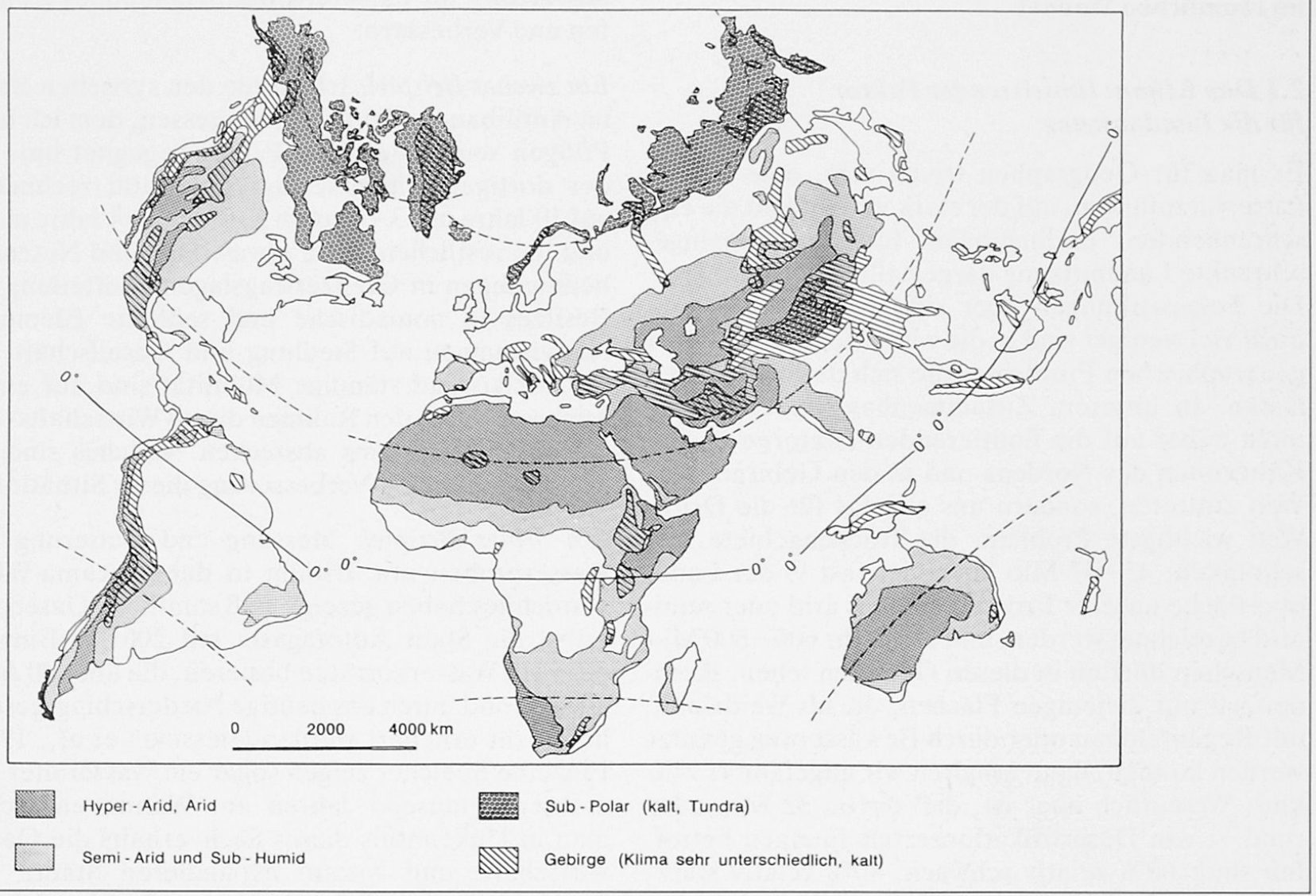

Abb. 2 
keit zeigt. Die größte und wirtschaftlich bedeutendste Agrarzone zieht sich von Nordamerika über Europa bis nach Asien hinein, wird im trockenen Kontinentinnern unterbrochen und setzt sich in China und Japan bis an die Pazifikküste fort. Ist es nicht erstaunlich, daß die großen politischen Machtzentren unserer Erde genau auf dieser Bandbreite liegen? Genügt die Erklärung, daß diese politisch-wirtschaftlichen Machtkonzentrationen auf einer hohen industriellen Entwicklung basieren, oder müßten wir uns nicht vielmehr fragen, warum gerade in dieser Zone eine so hohe industrielle Entwicklung überhaupt möglich war? In Kenntnis der limitierenden Faktoren hat Hans Bösch die Grenzen der Landnutzung durch aride und feucht-tropische $\mathrm{Be}$ dingungen eindrücklich dargestellt, ganz abgesehen von den Kältebegrenzungen in den arktischen Bereichen und in den Gebirgen der Welt. Selbstverständlich müßte diese Karte heute aufdatiert werden, aber sie zeigt doch, basierend auf den in den 60 er Jahren verfügbaren Daten, eine deutliche Gliederung der Welt in Zonen, die von der Natur begünstigt oder benachteiligt sind. Diese Idee - die physisch-geographische Seite stärker betonend - möchten wir aufnehmen, um im Blick auf die Dritte Welt zu fragen, welche limitierenden Faktoren auftreten und wie sie sich auf Natur und Mensch auswirken.

\section{Die Naturgrundlagen der Dritten Welt im räumlichen Wandel}

\subsection{Das Klima: limitierender Faktor für die Landnutzung}

Es mag für Geographen trivial sein, eine Klimakarte vorzuführen, auf der stark vereinfacht die einschränkenden Bedingungen für eine uneingeschränkte Landnutzung dargestellt sind (Fig. 2).

Die Folgewirkungen aber sind nicht trivial, und noch viel weniger sind es die wissenschaftlichen und geographischen Probleme, die sich daraus ableiten lassen. In unserem Zusammenhang möchten wir nicht näher auf die limitierenden Faktoren in den Kältezonen des Nordens und in den Gebirgen der Welt eintreten, sondern uns auf das für die Dritte Welt wichtigste Problem, die Trockengebiete, beschränken: $45-47$ Mio $\mathrm{km}^{2}$ oder fast $1 / 3$ der Landoberfläche unserer Erde müssen als arid oder semiarid bezeichnet werden, und ungefähr 600-800 Mio Menschen dürften in diesen Gebieten leben. Rechnen wir nur diejenigen Flächen, die als Weideland, mit Regenfeldbau oder durch Bewässerung genutzt werden können, dann erhalten wir ungefähr $41 \mathrm{Mio}$ $\mathrm{km}^{2}$. Wesentlich aber ist, daß davon 32 Mio oder rund $3 / 4$ von Desertifikationserscheinungen betroffen sind: $60 \%$ relativ schwach, $40 \%$ relativ stark, und vielleicht $0,1 \%$ ist so weit degradiert, daß eine Regeneration unmöglich oder zumindest sehr auf- wendig ist. (MENSCHING und IBRAHIM, 1977, MESSERLI, 1980, und DREGNE, 1987).

Diese wenigen und knapp zusammengefaßten Daten erlauben uns, die folgenden Fragen methodischer und fachlicher Art zu stellen: Wie zuverlässig sind diese Daten? Wie gut läßt sich die Dynamik dieses Prozesses erfassen? Wie spielen menschliche Tätigkeit und natürliche Ursachen zusammen? Welches sind die Konsequenzen für Gesellschaft und Wirtschaft? Viele Fragen sind offen, und wir müssen uns über eines klar sein: die Probleme sind nicht weltumspannend anzugehen und zu lösen, sie erfordern unseren Einsatz an einem bestimmten Ort mit seinen ganz bestimmten ökologischen, ökonomischen und sozio-kulturellen Bedingungen. Nur in dieser räumlichen Beschränktheit kann ein so komplexes Problem ganzheitlich angegangen, können mögliche Maßnahmen erarbeitet werden.

Ein erstes Beispiel: Wenn Tunesien noch vor kurzer Zeit seine gesamte Bevölkerung aus dem eigenen Boden ernähren konnte und heute zu einem der größten Nahrungsmittelimporteure der Dritten Welt geworden ist, um seine degradierten und unproduktiv gewordenen Flächen im Innern auszugleichen, ist dies auf Übernutzung und veränderte wirtschaftliche Bedingungen oder auf die in den letzten Jahren stark verminderten Niederschläge zurückzuführen? Oder ist es eine Summation von beidem? Die Kenntnis dieses Prozesses ist die Voraussetzung für ein sinnvoll korrigierendes Eingreifen und Verbessern.

Ein zweites Beispiel: Ich werde den syrischen Bauer im Antilibanon nicht mehr vergessen, dem ich beim Pflügen seines steinigen Feldes begegnet bin. Mit der dortigen Niederschlagsvariabilität rechnet er auf 10 Jahre mit 3-4 guten Ernten, 3-4 Jahre nichts und die restlichen Jahre etwas. Das sind Nutzungsbedingungen in Grenzertragslagen. Aufteilung des Besitzes in nomadische und seßhafte Elemente, Auswirkungen auf Siedlung und Gesellschaft, hohes Risiko und ständige Mobilität sind nur einige Stichworte, die den Rahmen dieses Wirtschafts- und Gesellschaftssystems abstecken. Welches sind die Möglichkeiten zur Verbesserung dieser Situation?

Ein drittes Beispiel: Messung und Datierung von Wasserproben mit Tritium in der Atacama-Wüste Nordchiles haben gezeigt, daß sämtliche Oasen und selbst die Stadt Antofagasta mit 200000 Einwohnern auf Wasservorräten basieren, die über 40 Jahre alt sind und durch das heutige Niederschlagsgeschehen nicht erneuert werden (MESSERLI et al., 1989). Einzelne Speicher zeigen sogar ein Wasseralter von mehreren tausend Jahren an. Warum entwickelt man in Unkenntnis dieses Sachverhalts die Oasenwirtschaft, und warum expandieren Städte und Bergbau ohne Rücksicht auf dieses Problem? Welch anspruchsvolle Projektarbeit wäre hier zu leisten, 
von den naturwissenschaftlichen Grundlagen über die Analyse der wirtschaftlich-politischen Antriebskräfte bis zur Umsetzung und Implementation von angepaßten Maßnahmen?

Ein viertes Beispiel: Wir haben es im Tibesti-Gebirge der Zentralen Sahara erlebt, wie die Lebens- und Wirtschaftsweise der Tubu-Bevölkerung auf die Niederschlagszeiten ausgerichtet ist. Wir haben aber auch erlebt, wie tief die möglichen Hungermonate vor der Dattelernte im Bewußtsein dieser Menschen verankert sind. Die Tragfähigkeit dieses Raumes ist begrenzt, das Gesetz des Minimums diktiert das Überleben. Es ist müßig festzustellen, daß weltweit mehr Nahrung zur Verfügung steht, als rein physiologisch erforderlich wäre. Die Illusion dieser Aussage zielt über Aspekte der Politik und des Güteraustausches hinweg zum Problem, daß eine Fremdversorgung ein labiles Ökosystem nicht stabiler macht, im Gegenteil: Widerstandskraft und Überlebenswille werden dadurch geschwächt, und als letzte Konsequenz folgt die Abwanderung nach einem stabileren Raum, das heißt: ein Zusammenbrechen von Kulturen und ein Entleeren großer Räume unserer Erde! Wir stehen vor einem Problem globalen Ausmaßes, das nur auf einer genauen
Kenntnis der ökologischen Grundlagen und der sozio-kulturellen Bedingungen an einem ganz bestimmten Ort verstanden und vielleicht einer Lösung zugeführt werden kann.

Die wenigen und willkürlich ausgewählten Beispiele mögen zeigen, wie vielschichtig und anspruchsvoll die Aufgaben sind, die in der klimatisch benachteiligten Trockenzone unserer Erde auftreten. Vor allem aber können diese Beispiele zeigen, wie groß die Möglichkeiten für ein Engagement der Geographen mit ihrer Methodik und ihrem Verständnis für die natur- und sozialwissenschaftlichen Bereiche sind, selbstverständlich unter Beizug der nötigen Spezialisten für ganz bestimmte Fragen.

\subsection{Der Boden: limitierender Faktor für die Landnutzung}

Für den Geographen mag auch die Bodenkarte (Fig. 3), vereinfacht und reduziert auf die Limitierung für die Landnutzung, trivial sein. Aber auch hier sind die Folgewirkungen für die landwirtschaftliche Entwicklung vieler Dritt-Welt-Staaten keineswegs trivial. Im Gegenteil, sie fordern zu spezialisierten und umfassenden Forschungsarbeiten her-

Der Boden: Limitierender Faktor für die Landnutzung

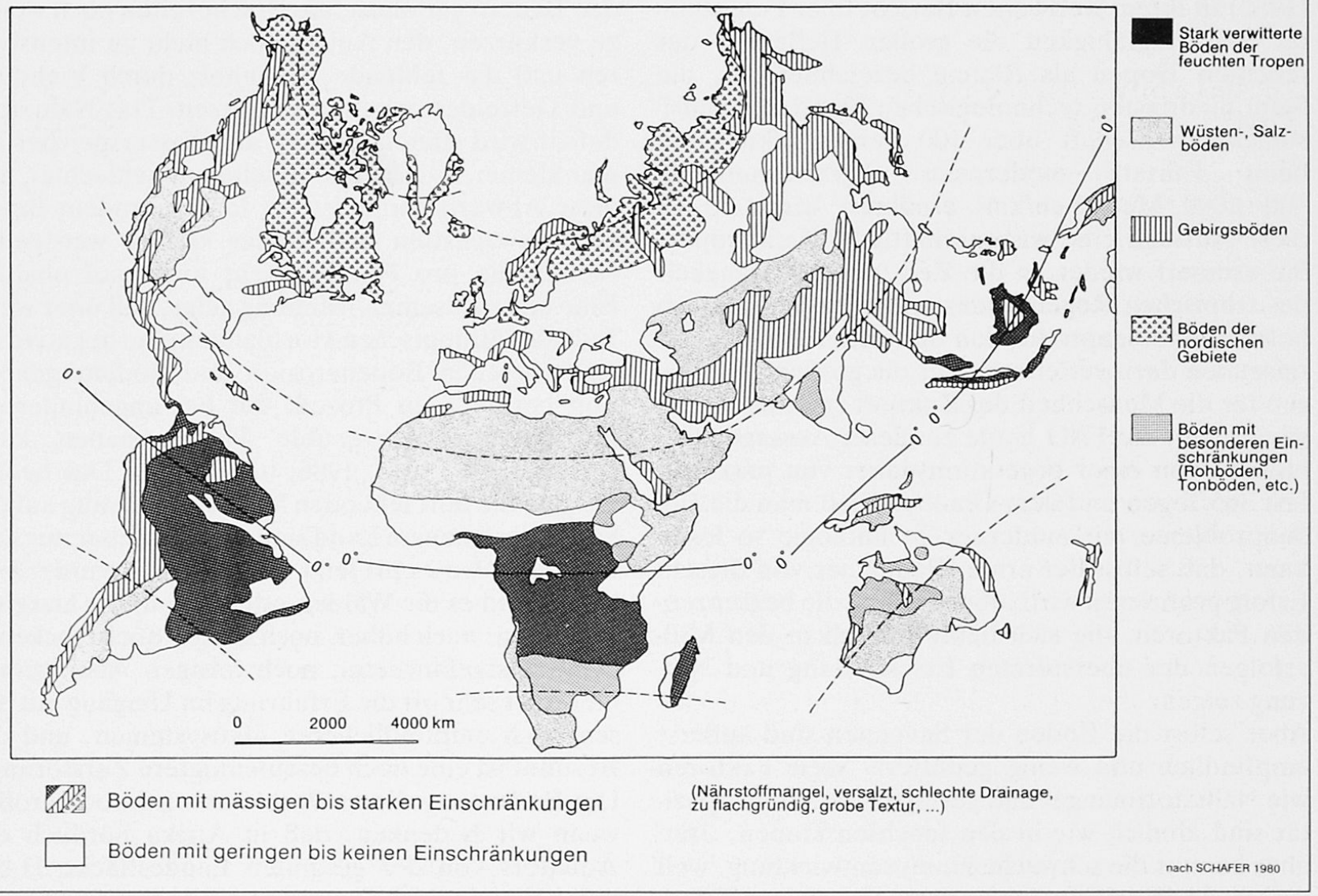

Abb. 3 
aus, indem auch hier jede Lokalität und jede Region ihr besonderes und individuelles Wirkungsgefüge von natürlichen und menschlichen Einflußfaktoren aufweist.

Unsere Medien berichten regelmäßig vom Raubbau an den tropischen Regenwäldern, aber wenig über den besonderen Nährstoffkreislauf des tropischen Regenwaldes und die schwerwiegenden Probleme der Bodennutzung nach einer Rodung. Ohne auf die spannenden Daten und Fakten zahlreicher, auch länger dauernder Feldexperimente einzutreten, zählen wir bloß summarisch die Faktoren auf, die in den feuchten Tropen die Bodenfruchtbarkeit einschränken: Versauerung, ungenügende Menge organischer Substanz, fehlender Restmineralgehalt, Aluminium-Toxidität und vor allem die geringe Kationenaustauschkapazität. Warum wurden die feucht-tropischen Niederungen mit ihren Regenwäldern bisher kaum erschlossen und nicht genutzt, warum dagegen die weniger feuchten Randgebiete und die klimatisch günstigeren Höhenstufen der Gebirge? Wären diese feucht-tropischen Räume hochproduktive Gebiete gewesen, hätten sich wohl andere Kulturen darin entwickelt, und die ErschlieBung wäre wohl früher und intensiver vor sich gegangen (WEISCHET, 1986, 1988).

Versuche mit modernster Agrartechnologie zeigen, welch gewaltiger Aufwand nötig ist, um einigermaßen gute Erträge zu erbringen, die erst noch mit hohen Risiken behaftet sind. Wenn also die FAO (1982) in ihrem weltweiten Bericht über Potentialität und Tragfähigkeit die großen Tiefländer der feuchten Tropen als Räume bezeichnet hat, die beim niedrigsten technologischen Stand der Subsistenzlandwirtschaft über 100 Personen $/ \mathrm{km}^{2}$ und beim Einsatz modernster Agrartechnologie 800-1000 Menschen $/ \mathrm{km}^{2}$ ernähren kann, so ist diese Aussage eine wissenschaftliche Katastrophe. Sie erinnert wieder an die Zeit, als die Üppigkeit des tropischen Regenwaldes und die offensichtlich hohe Biomassenproduktion die ersten Forschungsreisenden dazu verleitete, hier die großen Ressourcen für die Menschheit der Zukunft zu sehen. Aber wie kommt die FAO heute zu dieser Aussage? Geblendet von einer Vegetationsdauer von praktisch fast 365 Tagen und dem Glauben, daß man die Bodenprobleme mit moderner Technologie so lösen kann, daß selbst der arme Kleinbauer von diesem Erfolg profitieren wird, übersieht sie die begrenzenden Faktoren, die sich heute überall in den Mißerfolgen der überstürzten Erschließung und Nutzung zeigen.

Aber selbst die Böden der Savannen sind äußerst empfindlich und wenig gepuffert. Viele Faktoren wie Nährstoffmangel und geringe Austauschkapazität sind ähnlich wie in den feuchten Tropen, dazu aber kommt die schwache Humusentwicklung, weil die große Biomasse fehlt. Versuche an der Elfenbeinküste zeigen, daß die Regeneration einer Sa- vanne mit offenem Baumbestand nach einer Rodung äußerst schwierig und aufwendig ist. Sind semiaride Savannen in Kulturflächen umgewandelt, ist es äußerst fraglich, ob sie sich gemäß dem ökologischen Stabilitätsprinzip wieder in eine natürliche Savanne zurückverwandeln können (STANFORD und WANGARI, 1985: 23).

Dazu kommt ein weiteres: Bei der Nutzung der feucht-tropischen und der wechselfeucht-tropischen Räume, insbesondere in reliefierten und gebirgigen Gebieten, wird die Bodenerosion zum entscheidenden Prozeß. Fig. 4 zeigt auf der linken Seite einen tiefgründigen Boden, wie wir ihn in den wechselfeuchten Tropen eigentlich antreffen sollten, der über genügend Nährstoffe verfügt, einen guten Wasserspeicher bildet und bei sorgfältiger Nutzung gute Erträge liefert.

Demgegenüber sind degradierte Böden, auf der rechten Seite dargestellt, durch die Zerstörung ihrer Struktur nicht nur zunehmend anfälliger für Erosion, sondern sie werden auch immer ärmer an Nährstoffen und verlieren ihre Kapazität als Wasserspeicher. Das kann bedeuten, daß die Vegetationszeit durch fehlendes Bodenwasser um 20-30 Tage verkürzt wird, und gerade das kann bei ungenügenden Niederschlagsmengen oder einer unerwarteten Trockenphase ein entscheidender Faktor sein. Aber nicht nur das: Erodierte Böden sind nicht nur nährstoffarm und schlechte Wasserspeicher, sondern sie zwingen durch den ständig abnehmenden Ertrag den Bauern geradezu, die Brachezeiten noch weiter zu verkürzen, den Anbau noch mehr zu intensivieren und das fehlende Brennholz durch Viehdung und Getreidestoppeln zu ersetzen. Das Nährstoffdefizit wird ständig größer, der Wasserspeicher immer kleiner, die Erträge zunehmend schlechter, und diese Abwärtsspirale ist bei fortdauerndem Bevölkerungswachstum und immer kleiner werdenden Landfläche pro Familie nicht mehr aufzuhalten. Eine erste Zusammenstellung zeigt, daß über weite Teile des äthiopischen Hochlandes eine negative Bilanz zwischen Bodenerosion und Bodenregeneration besteht, ein Prozeß, der bei ungehindertem Fortschreiten irreversible Folgen haben kann (HURNI, 1983, 1985, 1986; ILCA, 1985). Das bedeutet, daß die dort lebenden Menschen ständig auf der Suche nach neuem Land sind. Land ist aber nur dort verfügbar, wo es bis jetzt nicht genutzt wurde: Entweder sind es die Wälder, oder es sind die marginalen Lagen: noch höher, noch steiler, noch trockener, noch frostgefährdeter, noch felsiger. Aber gerade hier fehlt sehr oft die Erfahrung im Umgang mit diesen noch empfindlicheren Ökosystemen, und das Resultat ist eine noch beschleunigtere Zerstörung. Die Bedeutung dieses Problems wird noch größer, wenn wir bedenken, daß in Afrika nördlich des Äquators von der gesamten Landesfläche 11,6\% durch Wasser- und 22,4\% durch Winderosion betroffen sind (FAO, 1986). Für Indien zeigen erste Hoch- 
NACHHALTIGE NUTZUNG

(Gleichgewicht)

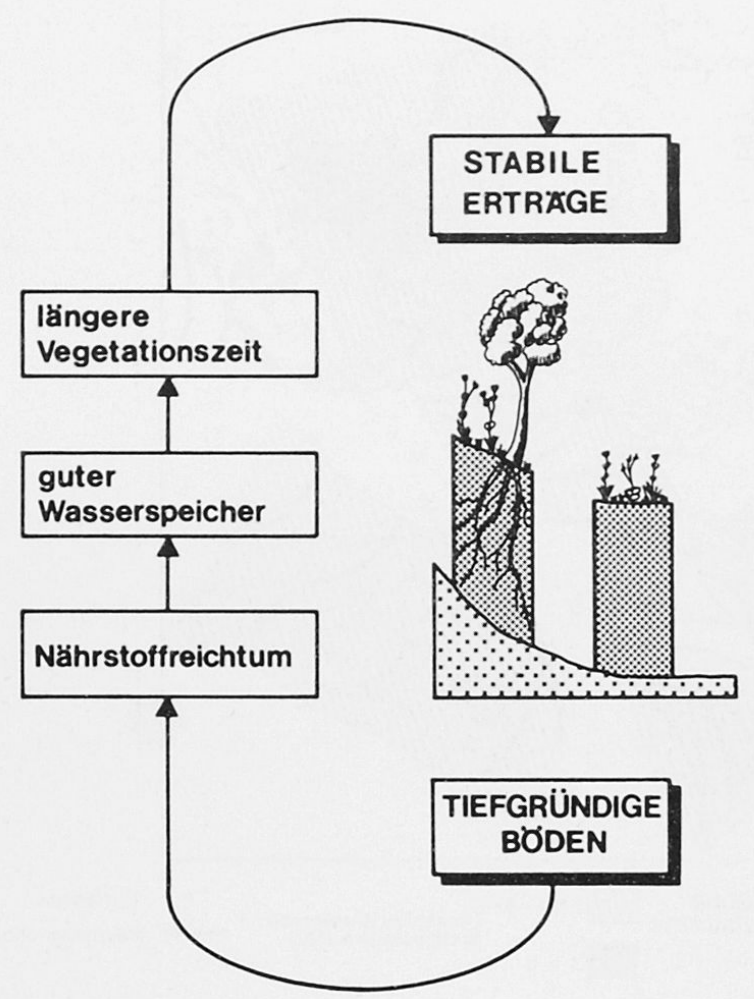

GESTORTE NUTZUNG

(Degradation)

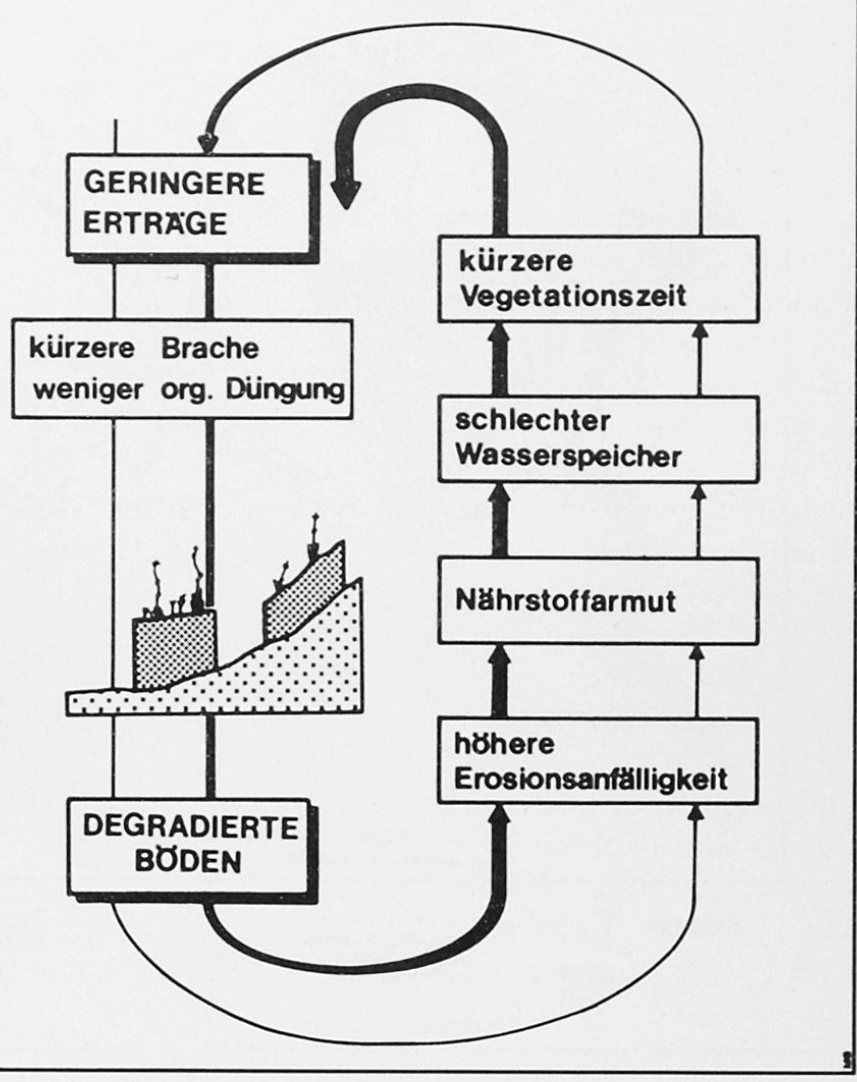

Abb. 4 (Messerli, 1986)

rechnungen, daß im Durchschnitt pro Jahr 16,35 t Boden/ha verloren gehen, aber nur 4,5-11,2 $\mathrm{t}$ wieder erneuert werden (NARAYANA und RAM, 1983). Wenn für die USA ein jährlicher Nährstoffverlust durch Bodenerosion von 50 Mio $t$ geschätzt wird (FAO, 1986), dann kann das durch künstliche Düngung mit einem gewaltigen Energieinput kompensiert werden, nicht aber in der Dritten Welt. Nach einer FAO-Berechnung wird die für den Regenfeldbau nutzbare Ackerfläche der Welt bis zum Jahre 2000 um 18\% sinken, wenn gegenüber heute keine Bodenkonservierungsmaßnahmen ergriffen werden. Die Produktion kann sogar um 29\% zurückgehen, weil die Erosion nicht nur Land zerstört, sondern - wie wir gesehen haben - auch Erträge reduziert. Das alles bedeutet, daß die Neulandgewinnung, die für Afrika nach verschiedensten Informationsquellen in großem Stile noch möglich sein soll, durch diesen Verlust wieder aufgehoben wird. Und das alles bei rasch wachsender Bevölkerung! «Wir rennen immer schneller, um letztlich doch still zu stehen!»

Was sind die Folgen? Instabilen und geschwächten Ökosystemen fehlt die nötige Pufferwirkung. Jede
Dürre wird zur Katastrophe und deckt die Mängel der Landnutzung und - sagen wir es so - die Fehler der Behörden und der Bewohner schonungslos auf! Das heißt mit anderen Worten, natürliche und anthropogene Einwirkungen sind aufs engste verknüpft, und es ist oft kaum mehr möglich, dieses Wirkungsgefüge zu zerlegen und den Anteil einer Komponente quantitativ und qualitativ zu erfassen. Wir stehen vor dem Problem, daß ökologische und sozio-ökonomische Prozesse aufs engste miteinander vernetzt sind. Wir müssen sie ganzheitlich sehen und doch auch mit Spezialistenwissen lösen. Eine fachliche und methodische Herausforderung - wir kommen darauf zurück.

\subsection{Die Naturgefahren: limitierende Faktoren für die Landnutzung}

Fig. 5 zeigt die großräumigen Naturgefahren. Wenn wir von den seismischen Zonen absehen, die sowohl die Industrie- wie die Entwicklungsländer betreffen, so sind es vor allem die tropischen Wirbelstürme, die in den Dritt-Welt-Staaten Asiens, Mit- 
Die grossräumigen Naturgefahren: Limitierende Faktoren für die Landnutzung

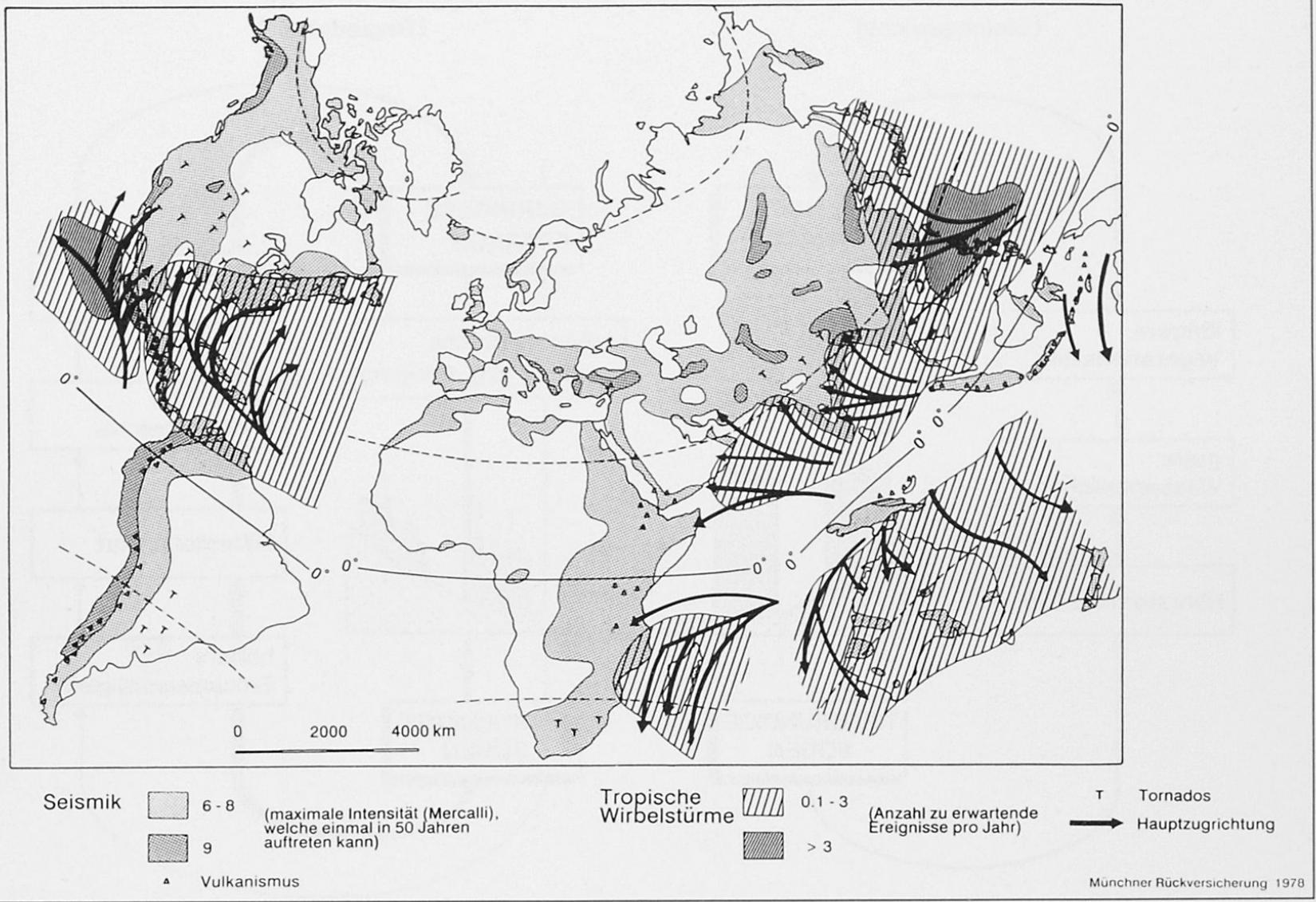

Abb. 5

telamerikas und in Teilen Afrikas große Schäden verursachen. Leider fehlen auf dieser Karte die regelmäßig wiederkehrenden, katastrophalen Überschwemmungen wie z. B. in Bangladesh, China usw. Wesentlich aber ist, daß die großräumigen Prozesse zwar nicht nur in der Dritten Welt vorkommen, dort aber unverhältnismäßig große Schäden anrichten, weil diese Staaten im Katastrophenfall nicht über genügende organisatorische und materielle Hilfsmittel verfügen.

Kleinräumig wirkende Gefahren wie Vulkanismus, Massenbewegungen, begrenzte Überschwemmungen usw. haben in der Dritten Welt genau gleich eine unverhältnismäßig große Schadenwirkung, weil die wachsende Bevölkerung immer mehr die gefährdeten Zonen nutzt und bewohnt. Dazu kommt, daß sehr oft menschliche Aktivitäten Katastrophen auslösen (Rutschungen, Stürze, Murgänge usw., durch Entwaldung, Straßenbau usw.), was wiederum die Vernetzung von natürlichen Prozessen mit menschlichem Handeln zeigt.

Man schätzt für die letzten zwei Jahrzehnte mindestens 3,75 Mio Tote, eine unbekannte Zahl von Verletzten und eine kaum zu beziffernde Schadensumme (MESSERLI et al, 1987, MITCHELL, 1989).
Die Bedeutung der Naturgefahren für die rasch wachsende Bevölkerung, insbesondere in der Dritten Welt, kommt darin zum Ausdruck, daß eine internationale Dekade zur Erforschung und Verhinderung oder Verminderung der «natural hazards» in Vorbereitung ist (US. Acad. of Sciences, 1987). In unserem Zusammenhang aber ist es wichtig, daß gerade die Geographen in der Planungsphase dieser Dekade immer wieder darauf hingewiesen haben, daß Naturgefahren nicht nur eine Sache der Naturwissenschaften seien, sondern ebenso sehr der Sozialwissenschaften, weil das Verhalten der Menschen letztlich die Größe der Katastrophe bestimmt (mündliche Mitt. G. White).

\section{Die Naturgrundlagen der Dritten Welt im zeitlichen Wandel}

Wenn wir die Erde heute in Gunst- und Ungunstzonen aufteilen, könnten wir leicht in den Glauben verfallen, daß das eine feste, gegebene Ordnung sei. Wir sollten uns aber immer wieder darüber klar werden, daß wir erdgeschichtlich einen Momentanzustand beobachten und daß wir alle unsere Über- 


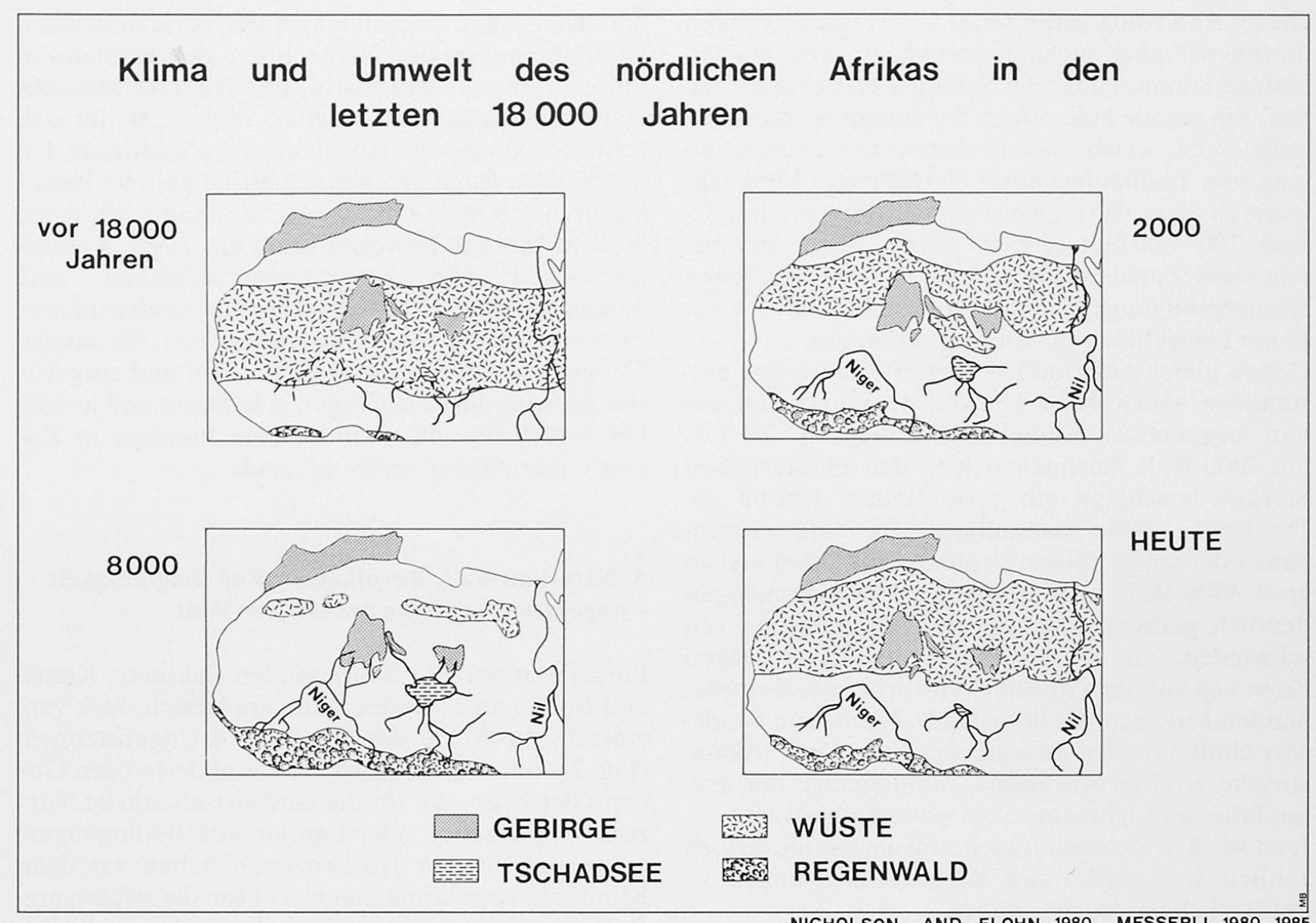

Abb. 6

legungen für die nächsten Generationen und das nächste Jahrhundert auf dieser möglicherweise sehr kurzfristigen Gegenwart aufbauen. Sollten wir nicht die Vergangenheit mit ihren bedeutenden Umweltveränderungen verstehen, um die Labilität und Zerbrechlichkeit unserer gegenwärtigen Ordnung in der richtigen Dimension zu sehen, dies um so mehr, als der Mensch nun energisch in dieses empfindliche Wirkungsgefüge eingreift? Was Professor Furrer mit seiner Schule für die Schweiz tut, haben wir versucht, für die nördlichen Teile Afrikas darzustellen (Fig. 6).

Das spannende Schauspiel in vier Akten beginnt mit einer außerordentlichen Trockenheit während der letzten Kaltzeit, was unter anderem auch zu einer starken Reduktion der tropischen Wälder führte. Zwischen 15000 und $10000 \mathrm{~B}$. P. erfolgte ein erstaunlicher und ökologisch äußerst wirkungsvoller Umschwung zur sogenannten holozänen Warmzeit. Für Afrika bedeutete das, daß die sommerlichen Vorstöße tropischer Luft nicht nur wie heute bis in den Sahel reichten, sondern über die Sahara hinweg den Rand des Mittelmeeres erreichten (MESSERLI, 1980, 1985; NICHOLSON und FLOHN, 1980). Im Südteil der Sahara bildeten sich offene Seen.
Der Tschadsee z. B., in den letzten Jahrzehnten zwischen 12000 und $25000 \mathrm{~km}^{2}$ schwankend, heute aufgrund der Niederschlagsarmut auf $1 / 10$ dieser Fläche zusammengeschrumpft (UNEP, 1988), war um 5000 B. P. $350000 \mathrm{~km}^{2}$ groß, fast so groß wie das Kaspische Meer und reichte vom nördlichen Kamerun bis an den Fuß des Tibesti-Gebirges in der Zentralen Sahara. Die verstärkte sommerliche Bewölkung und die erhöhten Niederschläge, die dadurch verminderte Verdunstung und die veränderten Abflußund Grundwasserverhältnisse ergaben eine völlig neue hydrologische Situation. In den heute extrem trockenen Gebieten kam es nicht nur zu Seen-, sondern auch zu Bodenbildungen, die heute noch als Paläoböden bedeutungsvoll sind. Eine offene Savannenvegetation, verdichtet entlang von stehenden oder fließenden Gewässern, erlaubte der afrikanischen Großwildfauna, bis an den Südfuß des Atlas zu wandern. In die gleiche Zeit gehören die Felsbilder der Sahara und zahlreiche Siedlungsplätze vom Atlantik bis zum Indik und vom Sahel bis an den Rand des Mittelmeeres. Zweifellos liegt der Beginn der ägyptischen, syrischen und mesopotamischen Hochkulturen in dieser holozänen Warmund Feuchtzeit. 
Dieses Bild völlig veränderter Umweltbedingungen dürfen wir aber nicht überzeichnen. Die Niederschläge könnten über der Sahara Werte erreicht haben, die gerade eine offene Savannenvegetation ermöglichten, welche sich höchstens in Galerien entlang von Flußläufen etwas verdichtete. Vielleicht konnten diese Werte, wo sie heute $100 \mathrm{~mm}$ sind, damals $200-300 \mathrm{~mm}$ erreicht haben. Eine sehr bescheidene Zunahme also, aber unter den gegebenen Grenzbedingungen gerade genügend, um das gesamte Umweltsystem völlig zu verändern.

Genau gleich empfindlich reagierte diese neu entstandene afrikanische Umwelt aber auch auf die nun beginnende Klimaverschlechterung. Bereits um 7000 B. P. zeichnen sich in den Flußterrassen Starkniederschläge mit torrentiellem Abfluß ab. Die Bodenprofile wechsellagern mit eingewehtem Sand oder eingespültem Grobmaterial. Aber erst ab etwa 4000 B. P. werden die Niederschlagsmengen deutlich geringer, die offenen Wasserflächen verschwinden, die geschlossenen Vegetationsdecken lösen sich auf, die Großtierwelt stirbt aus, die bestehenden Kulturen mit ihrer Jagd-, Fisch- und Weidewirtschaft brechen zusammen: Eine Umweltkatastrophe größten Ausmaßes, die diejenige der letzten Jahre und Jahrzehnte bei weitem übertrifft.

Jetzt werden Sie mich fragen, warum wir diese doch zeitlich weit entfernten Klimaveränderungen so ausführlich besprochen haben.

Zum ersten: Was ich Ihnen hier vorgeführt habe, ist eine von der Natur diktierte Klimaschwankung, die künftig im Bereich der menschlichen Einwirkungen liegen könnte. Eine globale Erwärmung um $1-2{ }^{\circ} \mathrm{C}$, wie sie sich für diese holozäne Warmphase abschätzen läßt, ist vielleicht schon zu Beginn des nächsten Jahrhunderts zu erwarten. Die Auswirkungen lassen sich heute kaum abschätzen, aber das Verhalten der tropischen Luftmassen wird über Glück oder Unglück eines großen Teiles der Entwicklungswelt entscheiden.

Zum zweiten: Unter ökologischen Grenzbedingungen haben die kleinsten Veränderungen, ob sie nun natürlich oder anthropogen verursacht sind, größte Wirkungen. Stabile Ökosysteme verfügen über eine ganz andere Pufferkapazität als labile. Das sollten wir bedenken, wenn wir die zunehmende Übernutzung der Ressourcen in den empfindlichen und marginalen Gebieten unserer Erde durch die rasch wachsende Bevölkerung in den kommenden Jahren mitverfolgen.

Zum dritten: Die Rekonstruktion der vergangenen Umweltveränderungen und die Entwicklung von Szenarien für die Zukunft hangen von einer intensiven Zusammenarbeit zwischen verschiedenen Disziplinen ab. Klimamodelle müssen durch Felddaten erhärtet und Felddaten durch modellmäßige Einordnung erweitert werden. In diesem Forschungs- bereich ist ein Zusammenwirken verschiedenster Disziplinen, von den Natur- bis zu den Humanwissenschaften, zur Rekonstruktion früherer MenschUmwelt-Systeme unabdingbar. Wenn z. B. für das zentralmexikanische Hochland eine Zerstörung der natürlichen Ressourcen durch altindianische Hochkulturen seit 4000 Jahren angenommen wird, dann braucht das zur Beweisführung ein enges Zusammenwirken von naturwissenschaftlichen und humanwissenschaftlichen Forschungsdisziplinen (WERNER, 1988). Dieses Zusammenspiel, für das die Geographie hervorragend vorbereitet und ausgerüstet ist, wird um so wichtiger, je häufiger und je stärker natürliche und anthropogene Prozesse in $\mathrm{Zu}$ kunft miteinander verknüpft sind.

\section{Naturhaushalt, Bevölkerung und Tragfähigkeit - ungelöste Probleme der Dritten Welt}

Projizieren wir die limitierenden Faktoren Klima und Boden aufeinander, dann ergibt sich stark vereinfacht die Karte der Gunst- und Ungunstzonen (Fig. 7), oder besser noch die Karte derjenigen Gebiete der Erde, die für die landwirtschaftliche Nutzung begrenzende oder limitierende Bedingungen aufweisen. In den Trockenzonen haben wir dem Klima als einschränkendem Faktor die wichtigere Rolle zugeteilt, obschon auch die Böden große Limitierungen aufweisen. In den feuchten Tropen dagegen haben wir die Böden als dominierendes Problem eingetragen, obschon auch das Klima mit der dauernden Schwüle und den in diesem Milieu lebenden Krankheitserregern wesentliche Einschränkungen vor allem für Mensch und Tier mit sich bringt. Ziehen wir Bilanz aus diesem knappen und summarischen Überblick, so heben sich aus der weltweiten Darstellung einige wenige Gunstgebiete mit relativ stabilen ökologischen Bedingungen heraus. Dazu gehören die mittleren Breiten der Nordhemisphäre mit den größten zusammenhängenden Flächen. Wir leben ganz offensichtlich im klimatisch bevorzugten Übergangs- und Begegnungsbereich zwischen polaren und tropischen Luftmassen mit ausgeglichenen Wärme- und Feuchtigkeitsverhältnissen und dementsprechend einer optimalen Ausbildung der Böden. Wir leben in einer der ökologisch stabilsten Zonen der Erde und sind uns dessen kaum bewußt.

Was heißt das in unserem Zusammenhang?

- Diese Sicht der Welt war vor wenigen Jahrzehnten noch nicht möglich. Es fehlten die Kenntnisse der weltweiten ökologischen Strukturen und Prozesse, um uns in diese Welt und Umwelt einzuordnen.

- Haben das alle unsere Schul- und Lehrbücher realisiert, oder leben wir heute immer noch im Bewußtsein, mit unseren $25 \%$ unproduktiven Flächen ein armes Land zu sein? Ägypten hat 97\% 
unproduktives Land. Ganz abgesehen davon bringt uns das sogenannt unproduktive Land mit seinem Tourismus als einem der wichtigsten Einnahmezweige der Schweiz einen bedeutenden Ertrag pro Jahr ein.

- Gerade unsere Alpen zeigen aber seit langem, was eine ökologische Benachteiligung bedeutet: verkürzte Vegetationszeit, verminderter Futterertrag, fehlender Ackerbau, Schwierigkeiten des
Bodens und des Reliefs mit all ihren ökonomischen Auswirkungen. Ist es nicht erstaunlich, mit welcher Selbstverständlichkeit wir in unserem kleinen und überblickbaren nationalen Rahmen als Resultat eines langen politischen Lernprozesses mit ökonomischen Mitteln diese ökologischen Benachteiligungen auszugleichen versuchen? Sollten wir Schweizer also nicht imstande sein, genau diese Problematik weltweit zu verstehen?

\section{GUNST - UND UNGUNSTRAUME DER ERDE}

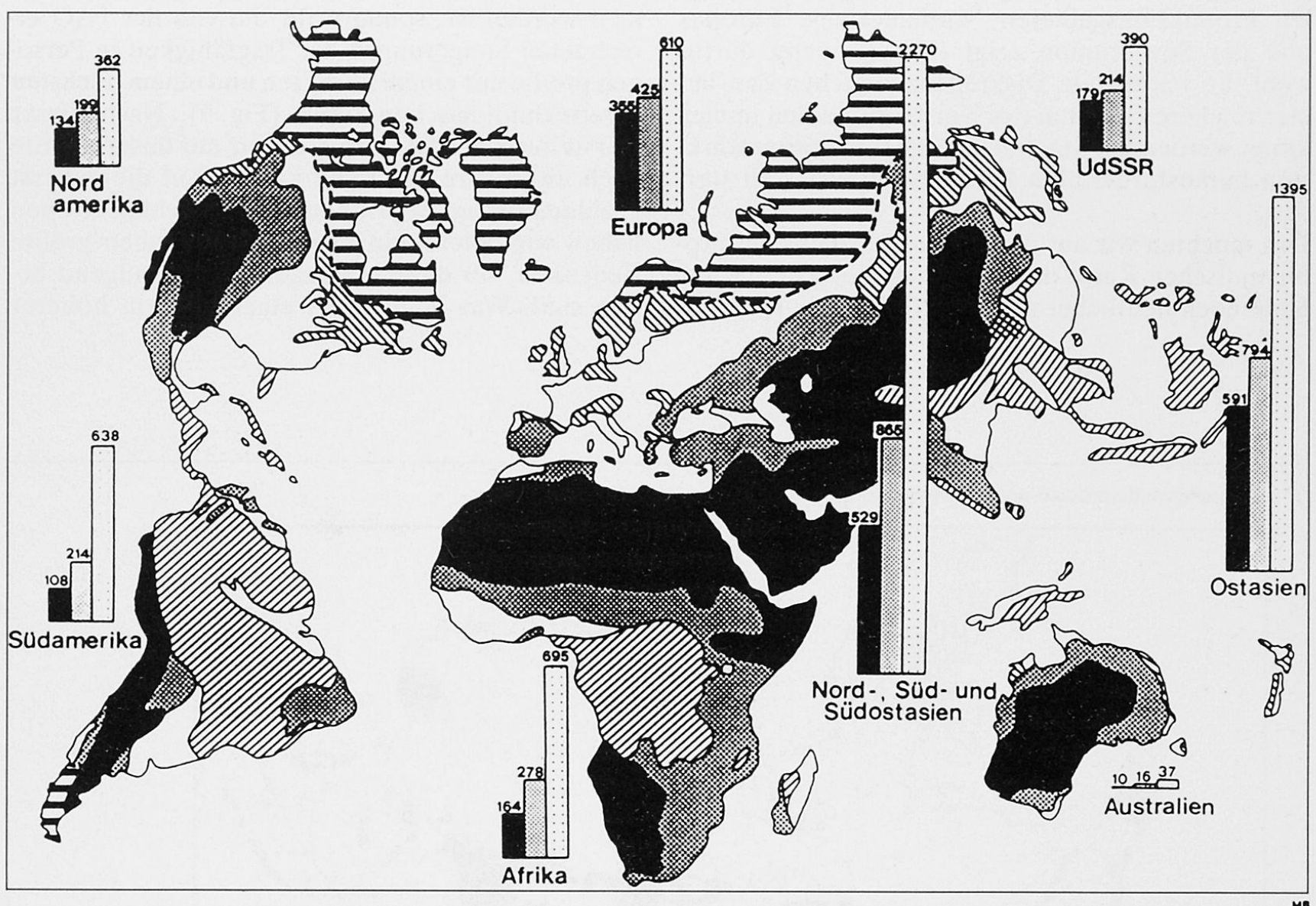

keine oder geringe Einschrănkungen

Dominante Einschränkungen:

Klima

Polargrenze des Getreideanbaus
Kältezonen
Trockengrenze des Regenfeldbaus
Trockenzonen
Semi-arid und sub-humıd

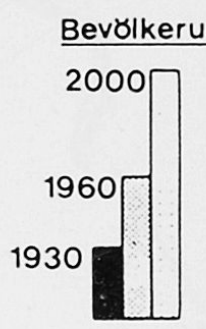

Boden

$\left.\begin{array}{ll}\text { DIIIS Tropen } \\ \text { AIIU Ausser-Tropen }\end{array}\right\} \begin{aligned} & \text { inklusive } \\ & \text { Gebirge }\end{aligned}$


Wir leben in einer ökologischen Stabilitätszone. Auf dieser Grundlage haben sich die großen Industrienationen des Nordens entwickelt, wir erleben jetzt, daß auch stabilen Ökosystemen Grenzen der Belastung gesetzt sind. Wie viel gefährdeter sind dann erst leistungsschwache und leicht verletzliche Ökosysteme! Müssen sie auf die Eingriffe des Menschen durch Nutzung und Übernutzung nicht noch viel empfindlicher reagieren? Wenn wir zudem bedenken, daß das Bevölkerungswachstum von 1930 bis 2000 - auch wenn es sich bloß um angenäherte Zahlen handelt - gerade in diesen empfindlichen Zonen erschreckende Zunahmen im Vergleich zu der sehr gedämpften Bevölkerungsentwicklung in den stabilen Produktionsgebieten Nordamerikas, Europas und der Sowjetunion zeigt (Fig. 7), dann dürfte wohl die wachsende Diskrepanz zwischen den immer reicheren Staaten des Nordens und den immer ärmer werdenden Staaten des Südens zum am stärksten herausfordernden Problem unserer Welt werden.

Das möchten wir auf der in mancher Hinsicht problematischen Karte der kritischen Gebiete unserer Erde noch deutlicher zeigen (Fig. 8). Die FAO hat
1982 die bereits erwähnten Karten über Potential und Tragfähigkeit herausgegeben. HARRISON (1983) hat aufgrund dieser FAO-Dokumente diejenigen Gebiete dargestellt, in denen beim heutigen einfachsten Stand der Anbautechnik («low-level input», d. h. eine Subsistenzwirtschaft ohne künstliche Düngung, ohne Pestizide und Herbizide, mit einfachsten Werkzeugen arbeitend usw.) die jetzt vorhandene Bevölkerungszahl die Tragfähigkeit bereits überschritten hat. MANSHARD (1984) hat die Daten regionsweise für die Jahre 1975 und prognostiziert auf das Jahr 2000 zusammengefaßt, aber nicht nur für den tiefsten technologischen Input, wie er für die kritischen Gebiete in Fig. 8 angenommen worden ist, sondern für die von der FAO errechneten Steigerungen der Tragfähigkeit in Personen pro/ha mit einem mittleren und einem höchsten agrartechnologischen Input (Fig. 9). Nach dieser Darstellung der FAO müßten wir auf unserer Erde noch ungeheure Reserven haben. Auf die äußerst problematische Beurteilung der feuchten Tropen haben wir bereits hingewiesen. Wir haben größte Bedenken, ob diese Aussagen auch genügend belegt sind. Was heißt denn eigentlich ein höherer

Nahrungsmittelproduktion und Bevölkerung

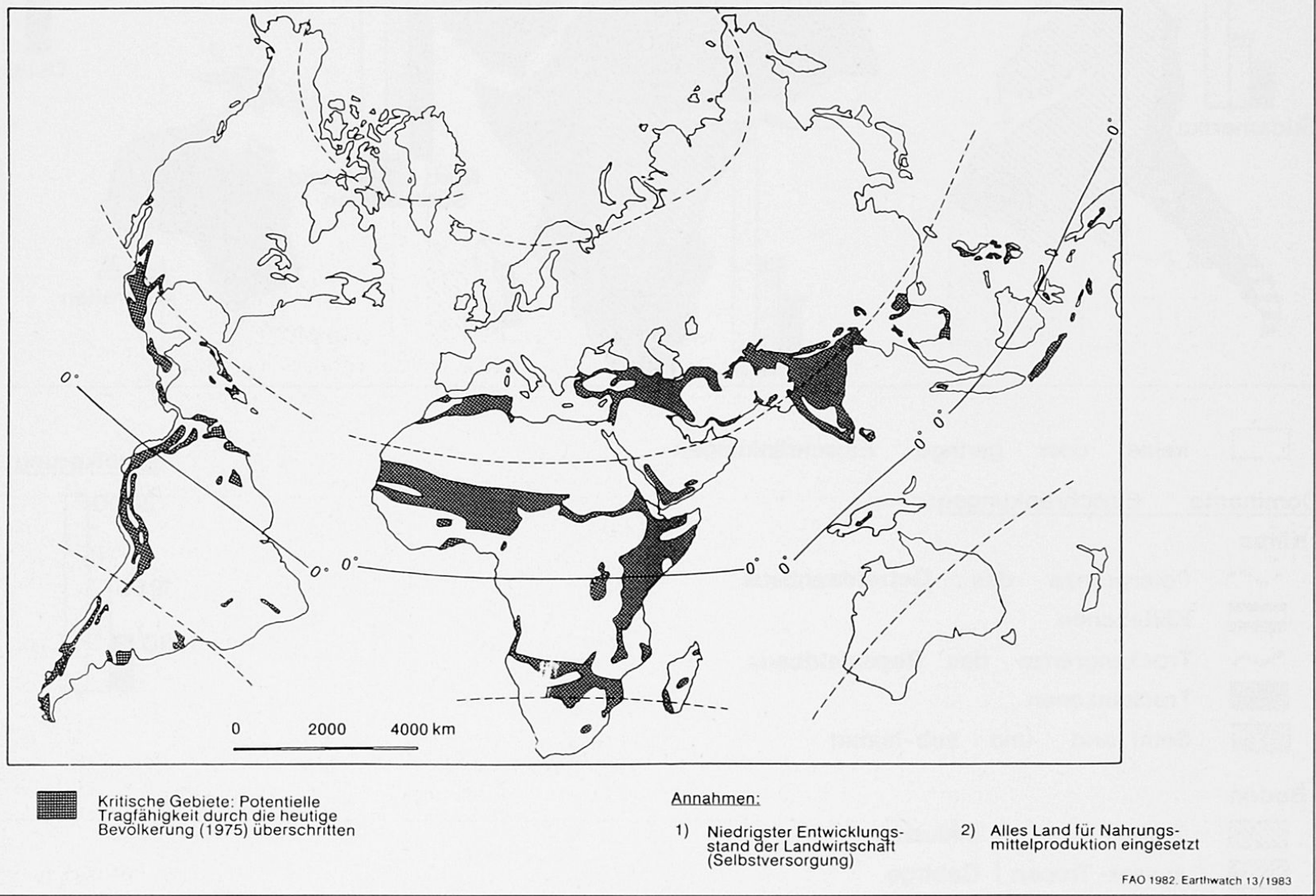

Abb. 8 
technologischer Input? Soll das so sein wie bei uns oder in den USA? Dort rechnet man jetzt für die Produktion von $1 \mathrm{kcal}$ tierischem Protein je nach Bedingungen 7-88 kcal fossiler Energie, für $1 \mathrm{kcal}$ pflanzliches Protein $0,7-3 \mathrm{kcal}$. Sind das Leitbilder für die künftige landwirtschaftliche Produktion in der Dritten Welt (PIMENTEL, 1987: 691)?

Ohne diese Probleme voll auszudiskutieren, möchten wir folgendes über diese Aussagen und Unsicherheiten festhalten:

- Unser Wissen über elementare, ja sogar existentielle Probleme unserer Welt und insbesondere der Dritten Welt ist sehr bescheiden, oder sagen wir es deutlicher: es ist völlig ungenügend. Stehen die Universitäten, ganz besonders diejenigen in der begünstigten Welt, nicht vor gewaltigen Aufgaben?

- Ist es richtig, daß wir jedes Jahr 6 Mio ha Land weltweit durch Erosion, Versalzung und andere Degradationsprozesse verlieren? Ist es richtig, daß die jährliche Pflanzenproduktion auf 20 Mio ha durch Bodenzerstörung auf fast Null reduziert ist oder sogar negative ökonomische Auswirkungen hat? Ist es richtig, daß nach FAO höchstens 4 Mio ha neues Ackerland jährlich erschlossen werden? Ist es richtig, daß der Fehlbetrag auf Ko- sten des verbleibenden Waldes geht? (PIMENTEL, 1987: 681). Für alle diese Fragen haben wir keine Antwort, wir können sie auch nicht global beantworten. Was wir aber brauchen, sind genaue Fallstudien, nicht um noch genauere Daten zu erheben, sondern um die Prozesse zu verstehen und um mögliche Lösungen und Maßnahmen zu ringen.

- Im Unterschied zu den langfristigen Umweltkatastrophen der Vergangenheit, die allein durch die Instabilität der Natur, d. h. durch Veränderungen der Zirkulationsstruktur oder der Interaktion Atmosphäre/Ozean gesteuert worden sind, werden die kurzfristigen Umweltkrisen der Gegenwart durch ein vernetztes Wirkungsgefüge von natürlichen und anthropogenen Einwirkungen bestimmt. Vielleicht dürfen wir sogar sagen, mit zunehmender Bevölkerung und wirtschaftlicher Entwicklung werden die anthropogenen Einwirkungen immer stärker.

- Aus neueren Berichten geht hervor, daß möglicherweise der Untergang der Mayakulturen um 900 n. Chr. von solchermaßen anthropogen ausgelösten Umweltkatastrophen mitbestimmt war. Das gleiche vermutet man für den Untergang des Reiches von Axum (Äthiopien) im 5. Jahrhundert, und schließlich erinnern wir uns an die Um-
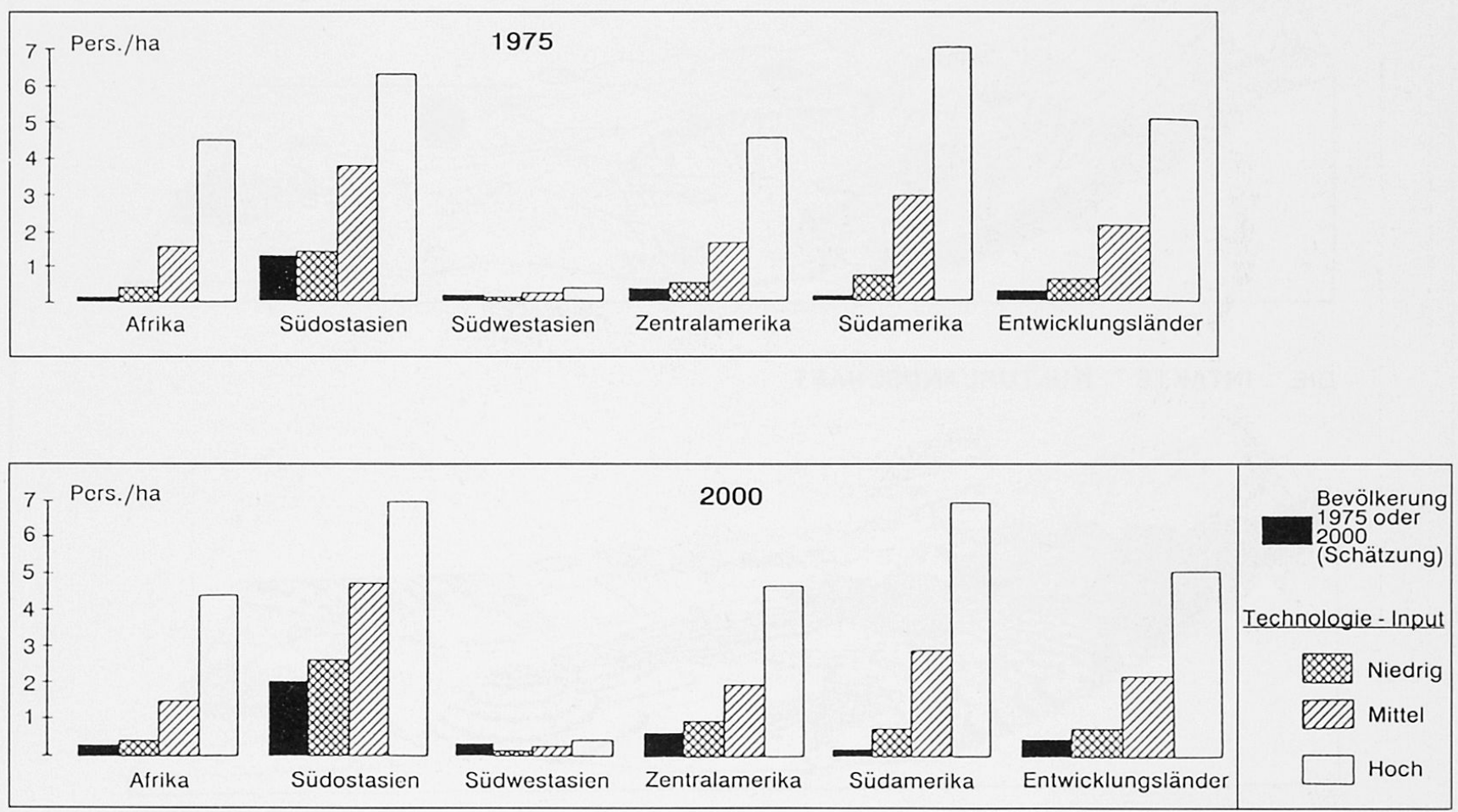

FAO 1982, Manshard 1984

Abb. 9 Bevölkerung und potentielle Tragfähigkeitskapazität in der Dritten Welt 1975 und 2000 (Manshard, 1984) 
weltzerstörung des Mittelmeerraumes in römischer und nachrömischer Zeit. Die kahlen und verkarsteten Flächen, die wohl in der holozänen Warmzeit einen Boden und eine Vegetation getragen haben, zeigen uns den Preis, den wir noch nach Jahrhunderten und Jahrtausenden für diese Handlungsweise zu bezahlen haben. Passiert jetzt genau das gleiche südlich der Sahara und in vielen Gebieten der Entwicklungsländer (MESSERLI, 1986)? Wir brauchen die Geschichtsforschung, um uns diese Prozesse und diese Wirkungen zu zeigen, die heute sozusagen unverstanden und schleichend vor unseren Augen ablaufen. Schließlich aber stehen wir vor der Frage, wie wir diesen Umweltveränderungen ( «global change») begegnen und wie wir die Aufgabe und die Verantwortung der Wissenschaft - und insbesondere auch unseres Faches - in diesem äußerst dynamischen Prozeß verstehen. Vergessen wir aber nicht: Heute geht es nicht mehr nur um die naturwissenschaftliche Frage des "global change», sondern bereits um die sozialwissenschaftliche und auch kulturgeographische Frage der «Human response to global change»!

\section{Geographie und Dritte Welt - Verantwortung und Zukunft}

Welche konkreten Ansätze sind möglich? Eine Antwort möchte ich mit Fig. 10 geben, die irgendwo im Himalaya, in den Gebirgen Afrikas oder in den Anden Südamerikas sein könnte. Durch Übernutzung sind Wald und Böden zerstört, die Ressourcen zum Leben und Überleben fehlen. Der Mensch in der erodierten Landschaft ist ein Individuum im Kampf ums Überleben. Wie kann er in einer Zeitdimension von Generationen denken, wenn er nicht weiß, wie er die Nahrung für morgen beschaffen soll? Er zerstört seine Umwelt, um zu überleben. Ein Boden wird in Jahrzehnten degradiert, der zu seiner Bildung Jahrtausende brauchte.

Ganz anders der Mensch in der intakten Kulturlandschaft: Er ist in eine Gemeinschaft eingeordnet: Aufforstung, Bewässerung, Terassierung, Verkehr, Energieversorgung usw. sind Elemente dieser Landschaft, die nicht vom Einzelnen, sondern nur von einer Gemeinschaft in einem funktionierenden politischen, wirtschaftlichen und sozialen Umfeld gemei-

\section{DIE ERODIERTE KULTURLANDSCHAFT}

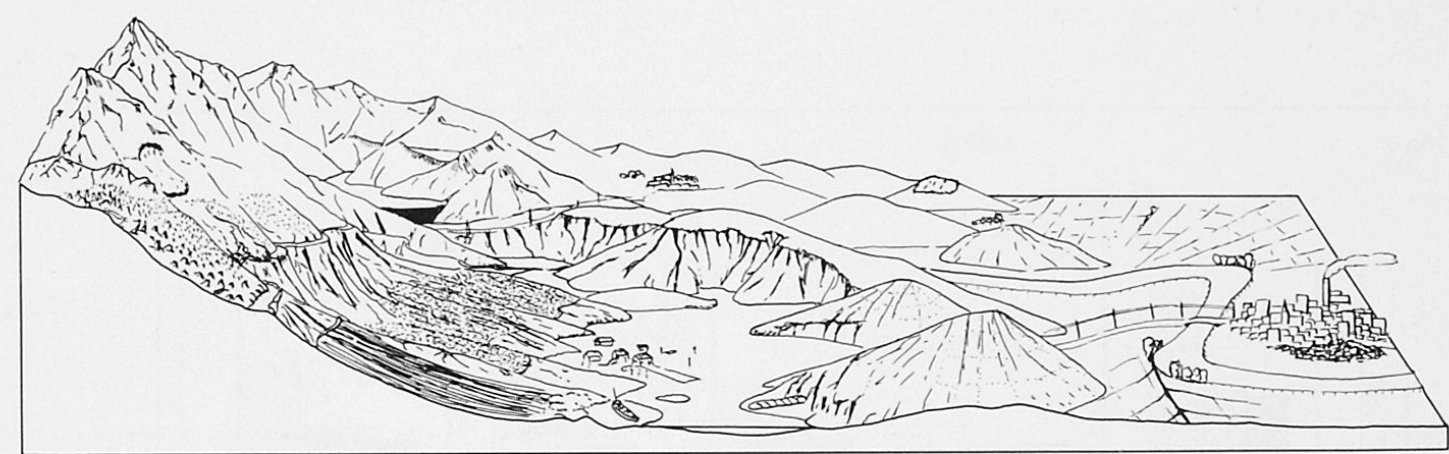

\section{DIE INTAKTE KULTURLANDSCHAFT}

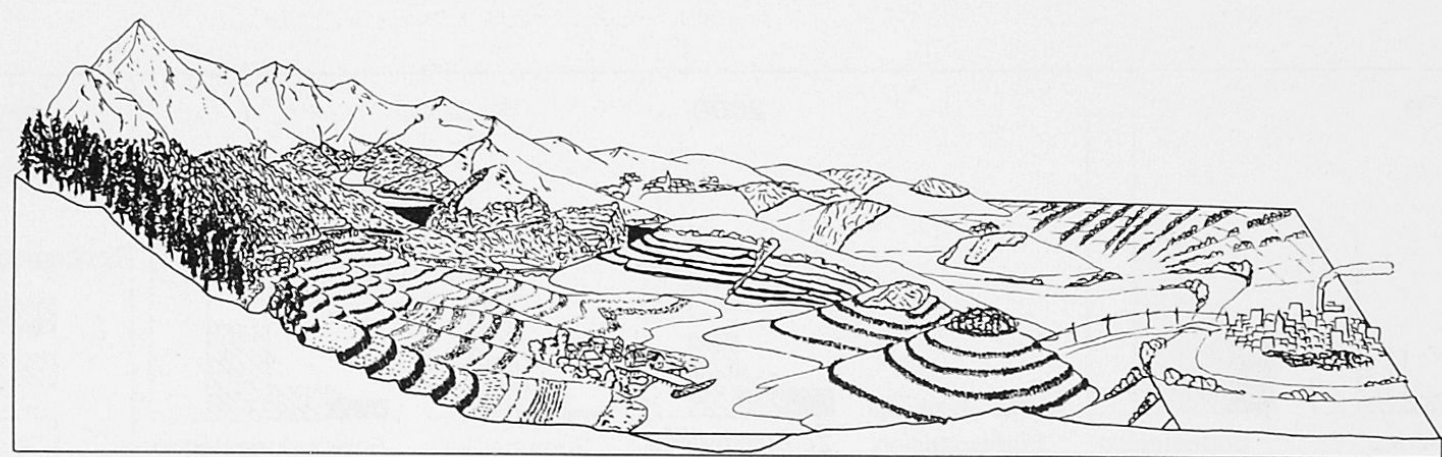


stert werden können. Ökologische Nutzung der Ressourcen setzt funktionierende ökonomische und politische Strukturen voraus. Dieser AufbauprozeB von der gestörten oder zerstörten zur regenerierten oder «reparierten» Kulturlandschaft enhält aber eine wissenschaftliche und ganz besonders eine geographische Herausforderung: Sind das nicht Aufgaben für die Geographie von heute und von morgen? Selbstverständlich braucht es dazu auch Spezialistenwissen, sei es von Geographen oder sei es von Agronomen, Förstern, Ingenieuren, Ökonomen, Ethnologen usw. Aber es braucht nur solche Spezialisten, die bereit sind, ihr Wissen und Können in ein vernetztes Wirkungsgefüge einzuordnen, nur solche, die menschlich und fachlich imstande sind, sich als bescheidener Teil eines Ganzen zu sehen. Leider ist diese Art von Wissenschafter noch allzu selten, vielleicht müßte zu seiner Förderung ein spezieller Nobelpreis vorgesehen werden! Dann aber, meine ich, sollten Geographen von ihrer Ausbildung und ihrem Wissenschaftsverständnis her die ersten sein, die diesen Preis erhalten.

In diesem Sinne bin ich überzeugt, daß die Geographie für die Probleme der Dritten Welt Wesentliches $\mathrm{zu}$ bieten und zu leisten hat. In einer Zeit, in der man sich in unserem Lande mit der Planung von Freizeitparks beschäftigt, bietet uns die Dritte Welt die Möglichkeit, an der Planung von «Überlebensparks» mitzuarbeiten: Ist diese Aufgabe nicht lohnender und nicht sinnvoller? Dazu aber braucht es ein neues Engagement mit einer hohen Verantwortung für eine Welt, an die zu glauben und für die zu arbeiten sich lohnt.

\section{Literaturverzeichnis}

BROWN, L. R., and WOLF, E. C., 1985: Worldwatch paper 25, Washington.

DREGNE, H. E., 1987: Desertifikation, Resources and World Development. S. Bernhard, Dahlem Konferenz: 697-710.

FAO, 1982: Potential Population Supporting Capacities of Lands in the Developing World. Report of Prof. INT/75/P 13 , Rome.

FAO, 1986: Protect and Produce. Soil Conservation for Development. I/Q 5110 E/3. 86/2/3000, 40 S.

HARRISON, P., 1983: Land and people, the growing pressure. Earthwatch No. 13: 8 S.

HURNI, H., 1983: Soil Formation Rates in Ethiopia. Working paper 2, EHRS, Addis Abeba.

HURNI, H., 1985: Erosion - Productivity - Conservation Systems in Ethiopia. ISCO Conference paper (unpublished).

HURNI, H., 1986: Soil Conservation Manual for Ethiopia. Ministry of Agriculture. Addis Abeba.

ILCA Bulletin, 1985: Moisture availability, cropping period and the prospects for early warning of famine in Ehtiopia. Bull. No. 21: 1-9.
MANSHARD, W., 1984: Bevölkerung, Ressourcen, Umwelt und Entwicklung. Geographische Rundschau 36, H. 11.

MENSCHING, H. and IBRAHIM, T. 1977: The problem of Desertification in and around arid Lands. Appl. Sciences and Development, Vol. 10: 7-43.

MESSERLI, B., 1980: Der Nord-Süd-Dialog. Ein ökonomisches oder ein ökologisches Problem. Berner Universitätsschriften. Die Dritte Welt und Wir. Haupt, Bern: 7-33.

MESSERLI, B., 1980: Die afrikanischen Hochgebirge und die Klimageschichte Afrikas in den letzten 20000 Jahren. Das Klima, Springer: 64-90.

MESSERLI, B., 1986: Universität und “Um-Welt» 2000. Berner Rektoratsreden. Haupt, Bern: 6-31.

MESSERLI, B., BISAZ, A., KIENHOLZ, H., WINIGER, M., BACHMANN, M., HOFER, T., LEHMANN, Ch., 1987: Umweltprobleme und Entwicklungszusammenarbeit. Bericht zu Handen der DEH. Geographica Bernensia P. 16: 47 S.

MESSERLI, B., BOBEK, M., GROSJEAN, M., SCHOTTERER, U., SCHREIER, H., 1989: Climate Change in the extreme arid Andes of Northern Chile (in Vorbereitung).

MITCHELL, K. J., 1989: Where might the International Decade for Natural Disaster Reduction concentrate its activities? A comparative analysis of disaster data sets. Rutgers University. Manuscript umpublished: $35 \mathrm{~S}$.

NARAYANA, D. V. V. and RAM, B. 1983: Estimation of Soil Erosion in India. Journal of Irrigation and Drainage Engineering. Vol. 109, 4, New Delhi.

NICHOLSON, S. and FLOHN, H., 1980: African Environmental Changes and the General Atmospheric Circulation in Late Pleistocene and Holocene. Climatic Change 2: 313-348.

PIMENTEL, D., 1987: Technology and Natural Resources. Resources and World Development. S. Bernhard, Dahlem Konferenz: 679-695.

SANFORD, W. et WANGARI, E., 1985: Dynamique et utilisation des prairies tropicales. Nature et Resources, UNESCO, Vol. XXI, No 3: 12-27.

UN-Conference on Desertification 1977: World map of desertification. AvConf. 74/2. Map 1: 25 Mio, Nairobi.

UNEP, 1988: News, Nairobi, April: 4.

UNESCO, 1984: Climat, sécheresse et desertification. Nature et Ressources, Vol. 20, 1, Paris.

US Nat. Acad. of Sciences, 1987: Confronting Natural Disasters. An Internat. Decade for Natural Hazards Reduction Nat. Acad. Press, Washington: $60 \mathrm{~S}$.

WEISCHET, W., 1984: Schwierigkeiten tropischer Bodenkultur. Spektrum der Wissenschaft Nr. 7.

WEISCHET, W., 1986: Die ökologische Benachteiligung südamerikanischen feucht-tropischen Tieflands - gegenüber Gebirgsräumen. Zbl. Geol. Paläont. Teil I, H. 9/10: $1127-1138$.

WEISCHET, W., 1988: Neue Ergebnisse zum Problem Dauerfeldbau im Bereich der feuchten Tropen. 46. Dt. Geographentag 1987. Tagungsbericht und wissenschaftl. Abh.: 66-85.

WERNER, G., 1988: Seit 4000 Jahren: Zerstörung natürlicher Ressourcen. Spiegel der Forschung 1. Justus Liebig Universität, Giessen: 10-11. 